\title{
PSYCHOLOGICAL DISTRESS EXPERIENCES OF INDIAN POPULATION DURING CORONAVIRUS DISEASE PANDEMIC SOCIAL ISOLATION AND LONELINESS: A CROSS-SECTIONAL STUDY
}

\author{
DIVYA GOEL ${ }^{1 *}$, MAJID FAROOQ ${ }^{2}$ \\ ${ }^{1}$ Department of Pharmacology, AIMS, Mohali, Punjab, India. ${ }^{2}$ Department of Pharmacology, Sher - i - Kashmir Institute of Medical Sciences, \\ Srinagar, Jammu and Kashmir, India. Email: drdivya74@gmail.com \\ Received: 09 April 2021, Revised and Accepted: 11 May 2021
}

\begin{abstract}
Objective: The sudden emergence of wide spread of the coronavirus disease 2019 (COVID-19) pandemic has led to adoption of physical distancing or lockdown all over the globe to curtail the viral transmission. Although lockdown plays an important role, at the same time, it can adversely affect the psychological health of the population. In addition, because of stay at home order, people are more inclined to use the media which can further aggravate the mental health issues in population. This study was planned to study the perceived psychological issues associated with the COVID-19 pandemic lockdown.
\end{abstract}

Methods: An online social survey was conducted using semi-structured questionnaire, participants were added through snowball sampling technique.

Results: A total of 455 people (264 females and 191 males) participated in the study. Majority of participants 228 (50.1\%) felt stressed out during coronavirus lockdown period. Female gender was associated with greater negative psychological impact of lockdown. Most participants 263 (57.8\%) were worried about the health of the loved ones. Most of the participants tried to seek information from different media. The difference between the stress level was highly significant $\left(\mathrm{p}=0.04639^{*}\right)$ between the participants depending on the duration for which they explore the information on different media.

Conclusion: COVID-19 pandemic was associated with stress in the majority of people in our sample, and media has a role to modulate the psychological impact of this lockdown. As COVID-19 pandemic is still ongoing, we need to verify these findings on larger population and policy-makers need to strengthen our mental health programs to mitigate the psychological impact of this pandemic.

Keywords: Coronavirus disease 2019, Pandemic, Mental health, Media, Stress.

(C) 2021 The Authors. Published by Innovare Academic Sciences Pvt Ltd. This is an open access article under the CC BY license (http://creativecommons.org/ licenses/by/4.0/) DOI: http://dx.doi.org/10.22159/ajpcr.2021v14i7.41752. Journal homepage: https://innovareacademics.in/journals/index.php/ajpcr

\section{INTRODUCTION}

Coronavirus disease (COVID) started in Wuhan city of China. China reported this to World Health Organization (WHO) on December 31, 2019 , as pneumonia of unknown cause. On January 30, 2020, the WHO declared this a Public Health Emergency of International Concern and declared a name for this new viral disease as COVID-19 [1]. COVID-19 quickly spreads across the world and the WHO on the March 11, 2020, declared COVID-19 - a pandemic [1]. Coronavirus is continuing its spread across the globe, as on now it has infected more than 5.4 million people in 188 countries and killing more than 340,000 individuals [2]. Because of sudden emergence of the coronavirus as of now we have very limited knowledge of this virus and also right now, there are no specific vaccines for treatment for COVID-19 [3]. As this virus spreads rapidly through droplets of saliva or discharge from nose, many countries across the globe are implementing measures to decrease the spread of the coronavirus such as national quarantines, closing of schools and restaurants, shutting off nursing homes, and stay at home orders [3]. Many researches have pointed out that spread of the COVID-19 is more fast because of movement of people with no or mild symptom, therefore, implementation of social distancing remains the corner stone to stop spread of coronavirus [4]. Although stay at home or lockdown measures are important to curb spread of corona virus, such stringent measures come with psychological cost and mental health problems [5,6]. Many studies have linked increased psychiatric morbidities such as depression, anxiety, panic attack, and long-lasting negative emotions with COVID-19 pandemic quarantine $[7,8]$. It is feared that the COVID-19 can lead to a "second pandemic" of mental health crises in communities [9].
In addition, because of the physical distancing measures, people are relying heavily on global digital social networks, to facilitate human interaction as well as to share information about the virus. The media might play a central role in pandemics as it is a powerful tool to influence people's opinion and action [10]. Studies have linked the excessive media exposure with increase in anxiety and stress [11]. "Cyberchondria" term has been coined as an abnormal behavioural pattern and emotional state, associated with anxiety amplifying effect of repeated or excessive health-related internet search [12].

Given the current situation with the COVID-19 pandemic, policy-makers need evidence to know the psychological impact of such lockdowns and study of various factors that could contribute to psychological well-being, and the factors which can mitigate these effects for the development of possible preventive and interventional programs. This study was planned with aim to investigate the health anxiety, cyberchondria, and virus anxiety during the COVID-19 pandemic in Indian population as there is dearth of data regarding these in India.

\section{METHODS}

A cross-sectional, observational study was carried out in North India. Participants were included using snowball sampling technique. An online, semi-structured questionnaire in English was developed using Google Forms. The link of the self-reported questionnaire was sent through social media (WhatsApp) and e-mails to the participants. The participants were encouraged to forward the link and enrol as manty participants as possible in this survey. On receiving and clicking the link, participants if accepted to be part of study filled the demographic details age, gender, occupation, and answered the set of multiple-choice questions seeking 
information related to anxiety associated with COVID pandemic lockdown and usage of media (new follow-up level) during this period.

It was an online study, only those who had access to internet participated in this study. The inclusion criteria for the participants in the study were an age of at least 18 years. As participants were filling out an anonymous questionnaire, permission for implied consent was taken from the Institutional Ethics Committee (IEC).

\section{Statistical analysis}

All data collected were analysed using descriptive statistics (proportion and frequency distribution) and inferential statistics (Chi-squared tests, $\mathrm{R}$ by $\mathrm{C}$ contingency table)

\section{RESULTS}

A total of 455 responses were recorded. Participation of females 264 (58\%) was more, as compared to males - 191 (42\%).

Out of 455 participants, 228(50.1\%) felt stressed out during coronavirus lockdown period. Female (53.40\%) felt more stressed out as compared male $(46.59 \%)$, and difference was statistically significant $(\mathrm{p}=0.0490)$. There was no statistical difference in the stress among different age category $(p=0.1136)$ but there was a significant difference $(p=0.003)$ in the self-reported stressed feeling according to the occupation of the participants (Table 1)

About 263 (57.8) participants feared about the health of the loved ones, while 167 (36.7\%) had concerns about their own health, 223 (49\%) participants reported change in their sleeping patterns during lockdown, and 181 (39.8) had change in their eating pattern during lockdown period. One hundred and thirty-nine (30.5\%) participants felt difficulty in concentration during lockdown period and 111 (24.4\%) participants felt disconnected from loved ones. Only 12 (2.6\%) participants self-reported the increase use of alcohol, tobacco during lockdown period (Table 2).

Table 1: Relationship between the stress and demographic of the participants

\begin{tabular}{llll}
\hline Variable & \multicolumn{2}{l}{ Stress } & p-value \\
\cline { 2 - 3 } & Yes (\%) & No (\%) & \\
\hline Gender & & & \\
Female & $141(53.40)$ & $123(46.59)$ & 0.0490 \\
Male & $87(45.54)$ & $103(53.92)$ & \\
Age (years) & & & \\
18-24 & $92(51.98)$ & $85(48.02)$ & 0.1136 \\
$25-34$ & $43(54.43)$ & $36(45.57)$ & \\
35-44 & $47(47.45)$ & $52(52.52)$ & \\
$45-54$ & $36(55.38)$ & $30(44.62)$ & \\
More than 55 & $10(29.41)$ & $24(70.59)$ & \\
Occupation & & & \\
Unemployed & $96(52.74)$ & $86(47.25)$ & \\
Job & $95(54.59)$ & $79(45.40)$ & \\
Freelancer & $9(32.14)$ & $19(67.86)$ & \\
Homemaker & $28(54.90)$ & $23(45.09)$ & \\
Retired & $3(15)$ & $17(85)$ & \\
\hline & & & \\
& & & \\
\hline
\end{tabular}

Table 2: Reactions of the participants during lockdown period

\begin{tabular}{ll}
\hline Responses & $\begin{array}{l}\text { No (\%) of } \\
\text { responses }\end{array}$ \\
\hline Fear about the health of loved ones & $263(57.8)$ \\
Change in sleeping pattern & $223(49)$ \\
Change in eating patterns & $181(39.8)$ \\
Fear about own health & $167(36.7)$ \\
Difficulty in concentrating & $139(30.5)$ \\
Restlessness & $128(28.1)$ \\
Feeling of disconnected from loved ones & $111(24.4)$ \\
Worsening of chronic health problems & $27(5.9)$ \\
Increase use of alcohol, tobacco, or other drugs & $12(2.6)$ \\
\hline
\end{tabular}

To deal with stress of lockdown period, 279 (61.3\%) participants tried to engage in some activity they enjoy, 204 (44.8\%) participants preferred to talk with other people to beat their stress. One hundred and ninety-nine (43.5\%) participants exercised regularly during lockdown and 11 (42\%) participants tried to eat well balanced meal during lockdown period. Forty-eight (10.5\%) participants avoided alcohol during this period and equal number of participants donated for a cause to deal with the stress during the lockdown period. Only $3(0.6 \%)$ participants meditate to beat stress during that time.

\section{Information seeking}

Out of 455 participants, nearly all the participants followed coronavirusrelated news, 356 (78.2\%) participants actively seek information from internet during lockdown period, $323(71 \%)$ participants watched T.V news to gain information about coronavirus, while only 143 (31.4\%) read newspaper to learn about coronavirus. Out of these, 71 participants watched only T.V news ( 24 stressed) and 111 participants seek information from internet (67 stressed) and there was statistical difference between stress level of both the groups ( $\mathrm{p}=0.00008^{*}$ ) About 201 (44.2\%) participants checked news related to coronavirus only once during the day and majority of participants $328(75.1 \%)$ spent only up to $1 \mathrm{~h}$ on news related to coronavirus. The difference between the stress level was highly significant $\left(p=0.04639^{*}\right)$ between the participants depending on the duration for which they explore the information on different media (Table 3).

\section{DISCUSSION}

The aim of this study was to examine the link between COVID-19 pandemic lockdown, its perceived impact on psychological outcome and cyberchondria. The study was done between May 18, 2020, and May 24,2020 , after 58 days of lockdown in India. In this study, nearly half of the participants self-reported anxiety associated with the COVID-19 pandemic lockdown. Pandemics are known to create period of uncertainty and lead to mental health issues in public [13]. However, most of the participants tried to engage either in some new activity, eat well-balanced diet, read books, and sleep to beat the stress due to lockdown. These positive emotional responses and keeping busy with these activities may have helped the participants to cope with the stress because of COVID pandemic lockdown, as the previous studies also have shown positive emotional attitudes lead to better psychological well-being [14,15].

In addition, females were found to suffer more from stress related to lockdown due to coronavirus, results were consistent with the higher prevalence of anxiety disorders among females, especially during the time of pandemic like this $[16,17]$.

Mass media influence the mental health of the people and can increase the anxiety in population, in our study, it was found that more spent time on different media by people make them more stressed out. Media is a powerful tool to disseminate the information widely to larger population in short span of time but information is different from misinformation, which is rampant nowadays. For example, both electronic and print

Table 3: Relationship between the stress and media

\begin{tabular}{llll}
\hline Variable & \multicolumn{2}{c}{ Stress } & \multirow{2}{*}{ p-value } \\
\cline { 2 - 3 } & Yes (\%) & No (\%) & \\
\hline T.V & $24(34.29)$ & $47(66.19)$ & $0.00008^{*}$ \\
Internet & $67(62.62)$ & $40(37.88)$ & \\
T.V+Internet & $67(58.77)$ & $47(41.23)$ & \multirow{2}{*}{$0.1991^{* *}$} \\
T.V+Internet+Newspaper & $45(51.14)$ & $43(48.86)$ & \\
T.V+Internet & $9(42.86)$ & $12(57.14)$ & \\
T.V+Newspaper & $6(35.29)$ & $11(64.71)$ & \\
Duration of media usage (per day) & & \\
Up to 1 h & $160(48.93)$ & $167(51.07)$ & $0.04639^{*}$ \\
1-2 h & $42(60.87)$ & $27(39.13)$ & \\
2-4 h & $13(65)$ & $7(35)$ & \\
More than 4 h & $5(29.41)$ & $12(70.59)$ & \\
\hline
\end{tabular}

$(*)$ : p-value is significant, $(* *)$ : $\mathrm{p}$-value is non-significant 
media play an important role as information provider but there were rumours about the spread of coronavirus through newspaper [18], which had been reflected in our study also as less number of participants seek information from newspaper as compared to T.V and internet. Media can play an important role in fostering a sense of social togetherness as we need physical distancing to limit the transmission of COVID-19 not social distancing. Social connections help people to cope with the stress during difficult times $[19,20]$

This study highlights the negative psychological outcomes during lockdown and inappropriate use of media which further creates mental health issues during this time. In the absence of effective preventive measure and pharmacological management of COVID-19, social distancing remains the best intervention to reduce the transmission of the virus, but as this study shows the need to expand our mental health support system in this on-going endeavour against COVID-19. At present, our health system is unequipped to take care of unmet mental health issued of the general population. Even when medical crisis is going to end, mental health crisis is going to come and we need to be prepared to handle that.

\section{Limitations of the study}

1. This was a cross-sectional study, so long-term impact of lockdown on psychological issues was not studied

2. It was study based on self-reported answers, date might be influenced by the social desirability and recall problems

3. Population surveyed was small, to generalize the date on whole population large-scale studies should be conducted all the India.

\section{CONCLUSION}

This study highlights the negative psychological outcomes during lockdown and inappropriate use of media which further creates mental health issues during this time. In the absence of effective preventive measure and pharmacological management of Covid-19, social distancing remains the best intervention to reduce the transmission of the virus, but as this study shows that for that there is need to expand our mental health support system in this ongoing endeavour against Covid-19. At present our health system is unequipped to take care of unmet mental health issued of the general population. Even when medical crisis is going to end, mental health crisis is going to come and we need to be prepared to handle that.

\section{ETHICS COMMITTEE}

IEC2038 ethical approval number.

\section{CONFLICTS OF INTEREST}

None.

\section{AUTHORS' FUNDING}

None.

\section{REFERENCES}

1. World Health Organization. Rolling Updates on Coronavirus Disease (COVID-19). Geneva: World Health Organization; 2020. Available from: https://www.who.int/emergencies/diseases/novel-coronavirus-2019/ events-as-they-happen. [Last accessed on 2020 May 26].

2. BBC News. Coronavirus Pandemic: Tracking the Global Outbreak; 2020. Available from: https://www.bbc.com/news/world-51235105. [Last accessed on 2020 May 26].

3. World Health Organization, Coronavirus; 2020. Available from: https:// www.who.int/health-topics/coronavirus\#tab=tab_1. [Last accessed on 2020 May 26].

4. Medical News Today. Why Social Distancing is Key in Containing the New Coronavirus; 2020. Available from: https://www. medicalnewstoday.com/articles/why-social-distancing-is-key-incontaining-the-new-coronavirus. [Last accessed on 2020 May 26].

5. Galea S, Merchant RM, Lurie N. The mental health consequences of COVID-19 and physical distancing: The need for prevention and early intervention. JAMA Intern Med 2020;180:817-8.

6. Courtet P, Olié E, Debien C, Vaiva G. Keep socially (but not physically) con-nected and carry on: Preventing suicide in the age of COVID-19. J Clin Psychiatry 2020;81:20com13370.

7. Brooks SK, Webster RK, Smith LE, Woodland L, Wessely S, Greenberg N, et al. The psychological impact of quarantine and how to reduce it: Rapid review of the evidence. Lancet 2020;395:912-20.

8. Yang Y, Li W, Zhang Q, Zhang L, Cheung T, Xiang YT. Mental health services for older adults in China during the COVID-19 outbreak. Lancet Psychiatry 2020;7:e19.

9. Choi KR, Heilemann MV, Fauer A, Mead M. A second pandemic: Mental health spillover from the novel Coronavirus (COVID-19). J Am Psychiatr Nurses Assoc 2020;26:340-3.

10. Limaye RJ, Sauer M, Ali J, Bernstein J, Wahl B, Barnhill A, et al. Building trust while influencing online COVID-19 content in the social media world. Lancet Digit Health 2020;2:e277-8.

11. Garfin DR, Silver RC, Holman EA. The novel Coronavirus (COVID-2019) outbreak: Amplification of public health consequences by media exposure. Health Psychol 2020;39:355-7.

12. Starcevic V. Cyberchondria: Challenges of problematic online searches for health-related information. Psychother Psychosom 2017;86:129-33.

13. Rubin GJ, Amlôt R, Page L, Page S. Public perceptions, anxiety, and behaviour change in relation to the swine flu outbreak: Cross sectional telephone survey. BMJ 2009;339:b2651.

14. Fredrickson BL, Joiner T. Positive emotions trigger upward spirals toward emotional well-being. Psychol Sci 2002;13:172-5.

15. Coping with Stress. Coronavirus (COVID-19), CDC; 2020. Available from: https:/www.cdc.gov/coronavirus/2019-ncov/daily-life-coping/ managing-stress-anxiety.html. [Last accessed on 2020 May 28].

16. Guo X, Meng Z, Huang G, Fan J, Zhou W, Ling W, et al. Meta-analysis of the prevalence of anxiety disorders in mainland China from 2000 to 2015. Sci Rep 2016;6:28033.

17. Gao W, Ping S, Liu X. Gender differences in depression, anxiety, and stress among college students: A longitudinal study from China. J Affect Disord 2020;263:292-300.

18. Newspapers as Fomites? Rumours, Declining ad Revenues Hit Media Hard as Newsrooms Double Efforts to Cover Coronavirus Pandemic, First Post; 2020. Available from: https://www.firstpost. $\mathrm{com} /$ india/newspapers-as-fomites-rumours-declining-ad-revenueshit-media-hard-as-newsrooms-double-efforts-to-cover-coronaviruspandemic-8288551.html. [Last accessed on 2020 May 29].

19. Rimé B. Emotion elicits the social sharing of emotion: Theory and empirical review. Emot Rev 2009;1:60-85.

20. Williams WC, Morelli SA, Ong DC, Zaki J. Interpersonal emotion regulation: Implications for affiliation, perceived support, relationships, and well-being. J Pers Soc Psychol 2018;115:224-54. 